\title{
The key is not to forget to be awesome: identifying narratives in an online community
}

\author{
Mariana Leyton Escobar* \\ 11413 Empire Lane, \\ North Bethesda, \\ MD 20852, USA \\ E-mail: leyton.mariana@gmail.com \\ *Corresponding author
}

\section{Piet Kommers and Ardion Beldad}

\author{
University of Twente, \\ Drienerlolaan 5, \\ 7500 AE Enschede, The Netherlands \\ E-mail: p.a.m.kommers@utwente.nl \\ E-mail: a.d.beldad@utwente.nl
}

\begin{abstract}
As online communities emerge in different settings all over the web, they continue to develop different ways to communicate online and to encourage participation in their activities. Scholars have proposed that one of the ways in which these communities do so is through the use of narratives. A case study was done on an open online community to establish if online communities develop narratives, what kind of narratives, and if these influence participation. This paper contains the analysis of the identifiable narratives that are useful to promote culture and participation and proposes three types of narratives that are more effective to do so. Implications of such findings and proposed future research are discussed.
\end{abstract}

Keywords: web-based communities; participation; narratives; YouTube; culture; Nerdfighters; community outreach.

Reference to this paper should be made as follows: Leyton Escobar, M., Kommers, P. and Beldad, A. (2014) 'The key is not to forget to be awesome: identifying narratives in an online community', Int. J. Web-Based Communities, Vol. 10, No. 4, pp.490-505.

Biographical notes: Mariana Leyton Escobar has received her BA from the University of Massachusetts and MS from the University of Twente.

Piet Kommers is an Associate Professor at the University of Twente, The Netherlands. His specialty is social media for communication and organisation. As conference co-chair of the IADIS multi-conference, he initiated the conferences of web-based communities and social media, e-society, mobile learning and international higher education. He is a Professor at the UNESCO Institute for Eastern European Studies in Educational Technology and he is an Adjunct Professor at Curtin University in Perth, Australia. 
Ardion Beldad is an Assistant Professor of Organisational and Corporate Communication at the University of Twente, The Netherlands, where he also obtained his $\mathrm{PhD}$. His research primary focuses on trust formation and maintenance both in online and offline contexts. Additionally, he also investigates the privacy concerns of internet users and their privacy-related behaviours.

\section{Introduction}

As online communities (OCs) emerge in different settings all over the web, community members are constantly trying different tools for communicating online and for encouraging participation in their activities. Faraj et al. (2011) proposed the idea that one of the ways in which such communities channel participation is by using narratives in order to help community members stay updated with what the community is doing, which would make it easier for them to participate and contribute. This is based on the idea that authors like Bruner (1991) and Brown (2006) have proposed, that narratives are good instruments to create culture and identity because of the way in which they help our minds make sense of reality.

Considering such propositions, this case study is aimed to find if narratives can be identified as tools for communication and for channelling participation in a specific OC that has shown high degrees of participation in the past. Two main exploratory questions were set:

- Are there identifiable narratives in this community's culture that have helped channel participation?

- What are the most effective narratives to do so?

To find answers to these questions, a survey was submitted to the community members of a chosen OC, inquiring if they could identify narratives that had helped shape the community's culture, the reasons for sharing such narratives, and their perception of how narratives affected their decisions to participate in community activities. The results were obtained through content analysis of the open answers by categorising what type of narratives were most essential according to the participants, as well as the reasons for sharing them. The last section of this paper explores theoretical and practical implications of the results.

\section{Theoretical framework}

\subsection{Online communities}

\subsubsection{Definition}

In general terms, OCs are groups of people who interact in virtual environments with some sort of purpose, following certain norms, and supported by technology (Preece et al., 2003). The term can be applied to different kinds of communities, which vary according to their type of activities, their online and offline presence, their purpose, size, 
duration of existence, stage in their life-cycle, governance structure, and the software environment that supports them (Preece et al., 2003; Yates et al., 2009).

Faraj et al. (2011, p.1224) provided a comprehensive definition of OCs as "open collectives of dispersed individuals with members who are not necessarily known or identifiable and who share common interests, [and] attend to both their individuals and their collective welfare". These authors also emphasise that OCs are "dynamic virtual spaces" and that they are "fluid organisational objects that are simultaneously morphing and yet retaining a recognisable shape” [Faraj et al., (2011), p.1225]. Moreover, OCs are highly fluid, but they are also continuous, so they can change their "boundaries, norms, participants, artefacts, interactions, and foci" over time, but remain essentially the same [Faraj et al., (2011), p.1226].

\subsubsection{Components of OCs}

There are four main components of OCs:

1 people, who interact socially while satisfying their own needs or performing special roles

2 a shared purpose, which can be an interest, need, information exchange, or service

3 policies, which can take the form of tacit assumptions, rituals, protocols, rules, and laws, that guide people's interactions

4 computer systems, which support and mediate social interaction (Maloney-Krichmar and Preece, 2002).

Looking at 'policies' from a social science perspective, which include tacit assumptions, rituals, etc., these can also be interpreted as being a community's culture - as it will be defined in Section 2.3 - which makes culture one of the components of an OC.

\subsection{Narratives in OCs}

\subsubsection{Narratives}

In order to better understand Faraj et al.'s (2011) proposition about channelling participation through narratives, this section dives into what narratives actually are and how they serve as essential building blocks of culture and identity, and how they can be used as tools for channelling participation.

Narratives are generally defined as spoken or written accounts of connected events, and Bruner (1991) explains that such accounts are what help us make sense of the world around us due to their specific features. He defines narratives as "a version of reality whose acceptability is governed by convention and narrative necessity rather than by empirical verification and logical requiredness" [Bruner, (1991), p.4], and explains that, as such, they serve as "instruments of mind in the construction of reality" [Bruner, (1991), p.6]. Taking Bruner's approach to narratives, Brown (2006) also explored several narrative features to better understand how they serve to create culture and identity. He argues that organisational actors use identity-relevant narratives "in their efforts to understand, or make sense of, the collective entities with which they identify" [Brown, (2006), p.734]. The key features of narratives proposed by these authors are 
explored in the following section. These features allow narratives to be tools to construct culture and identity.

\subsubsection{Key features of narratives}

First of all, narratives help us make sense of reality because they allow us to create mental models of how events relate to each other over time (Brown, 2006; Bruner, 1991). Additionally, people can interpret narratives individually or collectively because even though each narrative has specific details or particularities that distinguish it from others, they tend to be embedded in genres (which either represent different human plights, or, are ways of telling a story), and when we identify them, we become predisposed to "use our minds and sensibilities in particular ways" [Bruner, (1991), p.14]. To add to this, Bruner refers to the idea of referentiality, which is about how we make reference to elements within a story and to elements within its larger genre.

Another important aspect of narratives is that their interpretation is affected by contextual factors, which is something Bruner (1991) calls hermeneutic composability. Two important factors to consider are: the issue of intention (for both storyteller and listener, why is the story told?); and second, the issue of background knowledge (again, for both storyteller and listener), and how each interprets the other's background knowledge. Because the interpretation of narratives is so sensitive to contextual factors, Bruner (1991) explains that narrative discourse becomes a viable tool for cultural negotiation.

Other features of narratives to consider are normativeness and breach of canonicity, which mean that narratives that are worth telling are those that break away from the norm in some way - either because of what they are about or what their protagonist do, or because of the way in which they are told. Bruner (1991) talks about an intentional state entailment to refer to the idea that protagonists choose their own way regardless of their starting situation, which is why the narrative about him or her is worth telling.

Finally, the most important feature to consider for this paper is that of narrative accrual, which refers to the way in which narratives are made into a whole: "narratives do accrue, and, as anthropologists insist, the accruals eventually create something variously called a culture or a history or, more loosely, a tradition” [Bruner, (1991), p.18]. It is in this way that narratives work as tools for understanding our own reality and the reality around us.

When an OC, takes on the endeavour of identifying, sharing and collectively interpreting specific narratives, it is actively creating its own culture and providing itself with legitimacy and historical foundations (Bruner, 1991). Moreover, such endeavour, the process of joint narrative accrual, is one of the ways in which people work 'mentally' together (Bruner, 1991). This means that narratives are effective not only in helping create culture, but also in strengthening community cohesion, as narrative accrual is a collective, ongoing activity.

\subsubsection{Narratives and culture}

Schein (2004) proposed an understanding of organisational culture that can be applied to culture in OCs (Xiao, 2006). He defines culture as:

"A pattern of shared basic assumptions that was learned by a group as it solved its problems of external adaptation and internal integration, that has worked 
well enough to be considered valid and, therefore, to be taught to new members as the correct way to perceive, think and feel in relation to those problems." [Schein, (2004), p.17]

To understand culture formation, Schein (2004) talks about the socio-dynamic group theory, in which marker events influence members' perceptions about the group, as well as the formation of norms. For the author, culture happens whenever a stable group of people shares a significant number of problem-solving experiences that eventually leads them to share a view about the world (Schein, 2004). Going back to Bruner's (1991) theory, culture is formed by the constant collective accrual of narratives that are relevant to a group of people. These narratives can be about anything, including specific problem-solving instances the group experienced together. The stories about these critical events are then the narratives that group members use to make sense of their common history. It is in this way that both Bruner's and Schein's theories come together to explain culture formation through narratives in OCs.

\subsubsection{Channelling participation through narratives}

Channelling participation is about "identifying ways to keep interested participants informed of the current state of the OC's collaborative efforts” [Faraj et al., (2011), p.1232], with the goal of making it easier for them to take part and contribute. Narratives in this context are stories that explain 'a collective understanding' of how the OC has acted over time (Faraj et al., 2011). They are helpful by "creating a context for disembodiment of ideas, providing a temporary convergence, and allowing passionate and time-constrained participants to direct their efforts" [Faraj et al., (2011), p.1232].

Narratives, then, can serve a very specific purpose in the participatory behaviour of OCs. But before evaluating whether or not they serve this function, it must be evaluated if OCs are able to collectively identify and share narratives.

\subsection{OCs on YouTube}

\subsubsection{YouTube as a birthplace for communities}

YouTube is a video-sharing and social networking site created in 2005. Although its magnitude may not always reveal it, YouTube has a social core among its users, mainly between YouTubers - users who contribute original content to the site while collaborating and referring to one another (Burgess and Green, 2008) - and their audiences. Social relationships among content creators and between them and their audiences, "are characterised by strong cohesion around coherent semantic clusters of content" [Paolillo, (2008), p.8]. These users tend to form OCs of knowledge sharing around video creation and other topics. But while YouTube itself serves as the main platform for these communities, they are not only supported by one site. When YouTube's specific features are not enough for users to carry on a conversation, users develop analogue solutions to the perceived technological limitations (Burgess and Green, 2008), or proceed to using additional social networking sites that allow for extra interaction. The use of additional platforms improves the sociability of the communities, as it improves the way members interact with one another through supporting technology 
(Preece, 2001). This also allows for social ties to form, which is the step needed for audiences to become communities. Once YouTubers and their viewers are actively interacting with one another, sharing their practices and knowledge, and developing relationships, they are building OCs as they were defined in the previous section.

\section{The case: the Nerdfighter community}

The chosen community is the Nerdfighter community, which originated on YouTube in 2007, and proliferated through various online platforms (mainly Twitter, Facebook, Tumblr, Reddit, and various forums) over the years.

The origins of this community are rooted on a one-year video project by vloggers John and Hank Green entitled Brotherhood 2.0, which took place from January 1 to December 31 in 2007. Each brother would alternately upload four-minute vlogs to YouTube (http://www.youtube.com/vlogbrothers) and to their website (http://www.brotherhood2.com) every weekday for one year, creating an open, ongoing conversation about various topics - from personal anecdotes and opinions, to educational videos about science and politics. Its audience became particularly engaged with this content and started actively interacting with them - first through comments on the videos and through video responses on YouTube, and later through other platforms that would allow for more interactions. By moving on to other platforms, the audience became a community as the members started to create emotional bonds among each other. In this way, a sense of community was borne based on a shared enthusiasm for sharing knowledge; values based on philanthropy, equality, and empathy; shared interest in various popular culture topics; and the overall common enthusiasm in communicating through online channels.

Once the Green brothers noticed that a community was emerging from their audience, they realised they could nurture a knowledge sharing community that could get organised for various types of projects aimed at worthy causes. Notable projects include the Project for Awesome (a yearly collaborative and interactive public awareness campaign, which, in 2012, raised over \$USD480,000 for ten charities voted on by the community) and the Kiva Lending Team (a group at Kiva.org of over 40,000 Nerdfighters who have lent over \$USD2,000,000 by making over 80,000 different loans).

As these and other projects turned to be successes and the community that followed them grew larger and more cohesive, the Green brothers decided to continue posting vlogs after Brotherhood 2.0 ended, and they had continued to do so regularly since then. These videos are the backbone of the community, because they serve both as meeting points and as conversation starters for members. They are meeting points in the sense that when people gather around one platform to watch a video and proceed to interact with others in that platform, they are gathering in a networked public space (Boyd, 2011). And they are conversation starters because the topics that the Green brothers bring up are the ones that inspire community members to interact with each other by giving them something to talk about. These characteristics show that this community is worth exploring, as it has shown durability and growth over the past seven years, a strong sense of cohesion, a shared culture, and a great ability to become organised. 


\section{Method}

An Internet-based survey was created and posted in four different platforms in which Nerdfighters gather: two Facebook closed groups, a Nerdfighter subreddit and a Nerdfighter official Tumblr account. All of these four platforms are run by volunteers who have decided to either gather with other Nerdfighter according to interest or location (in the case of the Facebook groups), or who want to have a central meeting point for Nerdfighters within larger sites (in the case of Reddit, or Tumblr).

304 surveys were coded using a program called TAMSAnalyzer, and a Cohen's kappa of 0.749 was obtained with the help of a second coder. As participants reported specific stories or events that had taken place since the emergence of the community, they were coded as one specific narrative or accrued as one type of narrative according to how they fulfilled the key features of narratives explored in Sections 2.2.2 and 2.2.3. As an example of this, Table 1 exposes the most frequently mentioned narratives next to the main theoretical features they fulfil (these are developed further in Section 4.2 below).

Table 1 Narratives categorised by features

\begin{tabular}{ll}
\hline Narrative & \multicolumn{1}{c}{ Main theoretical features } \\
\hline $\begin{array}{l}\text { Fundraising events (Project for Awesome, } \\
\text { Kiva Lending Team and others) }\end{array}$ & $\begin{array}{l}\text { Marker events; breach of canonicity; intentional } \\
\text { state entailment; narrative accrual } \\
\text { Origins of the community }\end{array}$ \\
$\begin{array}{l}\text { Particularities; referentiality; breach of canonicity; } \\
\text { intentional state entailment; narrative accrual }\end{array}$ \\
Esther Earl & $\begin{array}{l}\text { Breach of canonicity; referentiality; intentional } \\
\text { state entailment; marker event }\end{array}$ \\
Inside Jokes & $\begin{array}{l}\text { Particularities; referentiality; narrative accrual } \\
\text { Breach of canonicity; referentiality; intentional } \\
\text { Narratives about the Green Brothers }\end{array}$ \\
\end{tabular}

\subsection{Participants}

Out of the 304 participants, $80.6 \%$ of were female, $17.1 \%$ male, and $2.3 \%$ reported other gender. The average age of the participants was $19.42(S D=5.08)$. In terms of education, the majority of participants reported being in or having finished either high school (44.7\%) or university at an undergraduate level (33.6\%). 5.6\% reported being in middle school, $9.9 \%$ in graduate university level, and $6.3 \%$ reported other. People from 26 countries were included in this analysis, though the majority was from the USA with $68.4 \%$, and from Canada with $10.5 \%$.

\subsection{Results}

The results were obtained by analysing the frequency and extensiveness of the different codes, as well as the intensity of the participants' responses. These elements were then interpreted by exploring whether or not they reflected any of the key elements of narratives discussed in Sections 2.2.2 and 2.2.3, as explained above. Various responses were selected as examples for each analysis whenever they would help exemplify an assessment. 


\subsubsection{Identified stories}

Respondents were asked to name any stories that they thought had helped shape the Nerdfighter community's culture. The aim of this question was to see if participants would collectively identify the same stories as the most prominent ones, as well as to see what type of stories would be chosen. The term 'stories' was used in order to make it easier for respondents to understand, but that term and the term 'narratives' are used interchangeably. As it can be observed in Figure 1, respondents agreed on several stories being most important. Again, only stories that were mentioned more than $3 \%$ of the times are included in the graph. To analyse these results, the components of narratives explained in Section 2.2.2 are referenced.

Figure 1 Identified stories, percentage of participants who reported each story

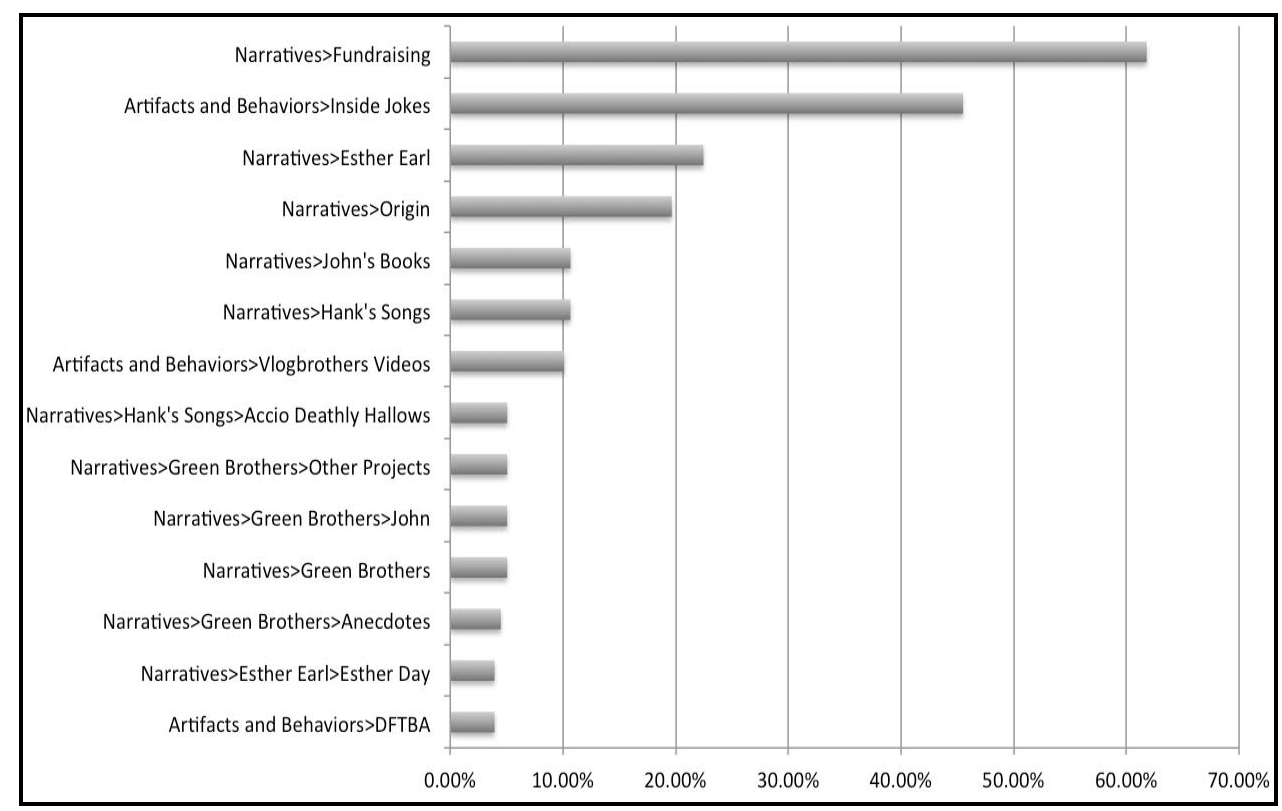

\subsubsection{Fundraising}

The most frequent type of stories that was mentioned was about fundraising projects. More specifically, stories about the Project for Awesome and about Kiva were mentioned $26.97 \%$ and $18.54 \%$ of the times, respectively, but Figure 1 shows an accrued percentage of mentions of other fundraising projects. In this context, respondents emphasised that the stories of how Nerdfighters had developed these projects together were essential foundations of the community's culture. These stories are so prominent because of their breach of canonicity, as these projects turned out to be great successes because of the very peculiar way in which they were organised. The following responses illustrate this point. 
"The community really came into being through the original Brotherhood 2.0 videos, when the Vlogbrothers defined the terms: Nerdfighteria, Nerdfighters etc., when they made up the gang sign, and when they said what we stood for: people who instead of being made from cells are made of awesome. Also when they first started donating to charities, by small amounts at first and it eventually became the Project for Awesome. Philanthropy is a big part of Nerdfighters being awesome."

"I think for sure the Project for Awesome is a big example. It's all about raising money for charities that we pick and it requires so much community involvement and every year we come together and do this really awesome thing to make the world a better place. Not many communities do that, or COULD do that, but we can and we do, and I think it helps reinforce what Nerdfighteria is all about: helping people, making the world a little more awesome, and having fun while doing it.”

When discussing the ways in which fundraising projects shaped the community, respondents also brought up the This Start Won't Go Out Foundation (TSWGO), the foundation that the family of Esther Earl (explained below) started in support for children with cancer and that Nerdfighters continuously support.

“All of the projects that Nerdfighters and Hank and John do such as Project for Awesome, helping with This Star Won’t Go Out [...] the Nerdfighter Kiva group continuously giving more and more money in loans to people in developing countries.”

"Too many. Project for Awesome is a fantastic celebration that symbolizes what most Nerdfighters long to be like: caring, giving individuals making a difference in their world. Esther Day 2012 was celebrated here in Quincy, MA last August 3rd-hundreds of Nerdfighters, most who didn't know each other, showed up to celebrate this holiday of loving family and those close to us.”

\subsubsection{Inside jokes}

The next most repeated topic among these answers was that of 'inside jokes', jokes that participants referred to as distinguishable stories that helped shaped this community's culture. Since they were so many, they accounted for the greatest percentage of responses in this case. Two things are worth noting about the inside jokes. First, how widespread among the community they are, regardless of how old or obscure they may be. And second, the fact that they reflect the element of referentiality explained by Bruner (1991), which refers to the way in which we make sense of narratives by referencing components within a larger context. Inside jokes only make sense within the context of a culture, so the fact that they are so widespread is evidence to the fact that the culture of this community is prevalent in spite of its size.

Some of the respondents, when asked to identify important stories for the community's culture, not only named the most prominent inside jokes but also reflected on their importance:

“This isn't necessarily a story, but understanding all of the silly little inside jokes is a huge part of who we are as a community. Not only are they a source of entertainment, but they also serve as a way to document our history." 
“There's a lot of little stories that I think help embellish what Nerdfighteria is. You can simply give someone a definition of the community, but I don't think they can understand how awesome it is without knowing about the inside jokes, French the Llama! Reading Johns amazing books, wondering about the Yeti, adding "your pants” after things, giraffe love, Hank humping things, the happy dance...”

\title{
4.2.1.3 Esther Earl
}

Esther Earl was a Nerdfighter whose story is very significant for Nerdfighters because she passed away very young, but she shared her views on the importance of love, family and friends in such a significant way that her memory is commemorated every year on her birthday - a holiday called 'Esther day'. Nerdfighters also show continuous support to the foundation her family founded, TSWGO (explained in the previous section).

The story of Esther was the third to be mentioned most at $22.47 \%$, and the TSWGO foundation and Esther day were mentioned 5.06\% and 3.93\% of the times, respectively. The recurrence and forcefulness of the comments that mentioned Esther Earl are evidence of the importance of this narrative in the Nerdfighter culture. The story of this young woman's courage and wisdom is a perfect example of a breach of canonicity in narrative and of a protagonist's intentional state entailment (Bruner, 1991), as the way in which she decided to live the last year of her life break away from conventional children with terminal illnesses. Moreover, one respondent mentioned that part of the reasons why this story was so significant was because it brought attention to the fact the community goes beyond its online borders.

\begin{abstract}
"John got to meet her and asked what she would like them to do. She responded with loving people who are close to you and ACTUALLY SAYING IT! Thus, Esther Day was born as a less cheesy Valentine's Day, but for family and friends and people you might not always say, "I love you" to. This event and her life changed the Nerdfighter community for the better and it continues to do so. It has created an event specific to Nerdfighters, but can also be shared with everyone."

"The life of Esther Earl and her impact on the Vlogbrothers helped to make the online community feel human. Because we are an online community, we do not often think about a member of the community dying, because it is online and the Internet is essentially undying."
\end{abstract}

\subsubsection{Origin}

The code 'Origin', which is the fourth most recurrent code that resulted in this question, was used anytime a respondent made a reference to any of the stories that occurred during the origin year of the Nerdfighter community. This includes Brotherhood 2.0 as a story itself, and every story that happened during it. This particular code involves many different stories, but no sub-codes were used because respondents tended to refer to the origin as a one comprehending story. The following responses were selected because they also show participants' thoughts on this narrative. 
"It started with a project, Brotherhood 2.0. It grew into a community."

"I like that Brotherhood 2.0 started as a way for John and Hank to get to know each other better, but wound up changing their lives and the lives of so many others. I think that's a key part of the Nerdfighter culture: it's founded upon a desire to get to know other people, or as John would say, imagine them complexly."

\subsubsection{Essential stories}

A follow up question asked participants if they thought there were any stories that they would consider essential to understand the Nerdfighter culture. In this case, the goal was to see if respondents would agree about what stories they would choose, or if they would consider that stories were important to understand the culture at all. Additionally, another aim of this question was to see what types of stories were more likely to stand out to members. Figure 2 shows the percentages of the responses to this question, which did not only include stories, but also other responses. The graph only includes responses that were repeated more than $3 \%$ of the time.

Figure 2 Essential stories, percentage of participants who reported each response

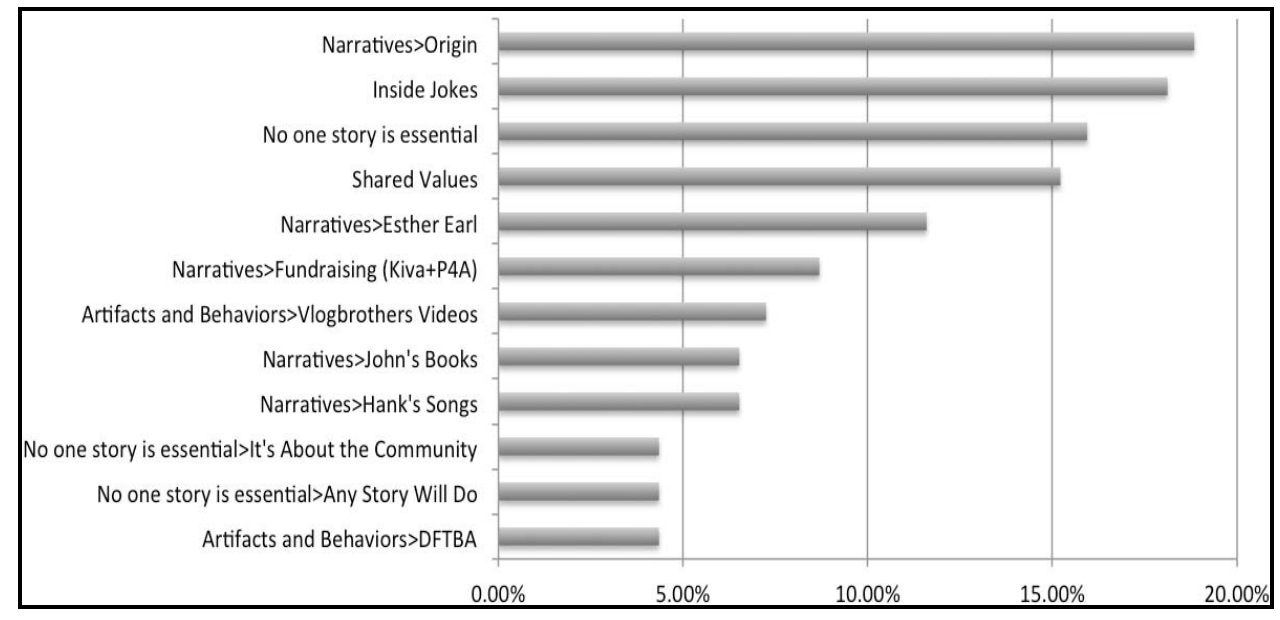

In these responses, participants explained that people who wanted to understand the culture (who they interpreted would be newcomers) may benefit from understanding who the Green brothers were, why they make videos, the format of the videos, the type of relationship they have with the Nerdfighter community, and the many inside jokes that they all share. The story that was most extensively named as essential to understand the community was the origin story. The next category of responses includes inside jokes. A participant explained this phenomenon best:

“Technically no, but we are a culture heavy on inside jokes so watching the 'must watch Vlogbrothers videos' playlist on their channel, if that's a thing you do, read a book or two of John's, glance over Hank's music. Just generally be aware of the things that go on in the community. But you don't have to be involved in all aspects of the community to be part of it." 
The third most frequent response was coded as 'no one story is essential', and it referenced the idea that many participants shared that there are no particular stories that a person needs to know in order to understand the culture. This sentiment was expressed in different ways, which accounted for creating different sub-codes, which included: 'any story will do', which refers to the idea that any story is good enough to understand the community; 'it's about the community', which refers to the idea that to understand the community one does not need to focus on stories or events, but on the community itself; 'it's a feeling', which was the idea that the community is not shared through stories, but through a feeling (i.e., a sense) of community; and 'it's personal', which refers to the idea that each person can choose what's essential for him or her, as the community is big enough to allow for that. For example, one participant stated:

"I think, as long as you know that this is a community founded on the idea of doing good things for others, and having a good time while doing so, that's all you really need to know."

At the same time, other responses reflected another feeling, stating that stories were important, but that there were not necessarily particular stories that were important:

"All events considering Nerdfighters and Nerdfighteria have shaped the community. If it's Esther's story, or the making of VidCon, or DFTBA Records all of them are our culture, our lifestyle.”

An interesting result from this question was that when asked directly about essential stories, $15.22 \%$ of participants expressed that understanding the values the community upholds was more important to understand the culture. For example, a responded stated:

"I think less 'stories' and more understanding the basic principles of Nerdfighteria.”

Other respondents shared this sentiment and picked specific values or principles they believed to be essential. Two examples were chosen to illustrate the type of values that were mentioned in this context:

"Mainly just the aim to decrease World Suck. The rest can be picked up, but that one is essential."

"Though there are many inside jokes, I think the only truly necessary part is our definition: that Nerds are allowed to be un-ironically enthusiastic and that Nerdfighters decrease World Suck."

\subsubsection{Sharing stories}

The next question asked participants that if they had ever shared any of the aforementioned stories with someone else, they explain why they had done so. The aim of this question was to understand why people would feel inclined to share these stories, to see if indeed the community's culture was formed by narrative accrual. Figure 3 shows the percentages of the responses to this question. 
Figure 3 Reasons to share stories, percentage of participants who reported each reason

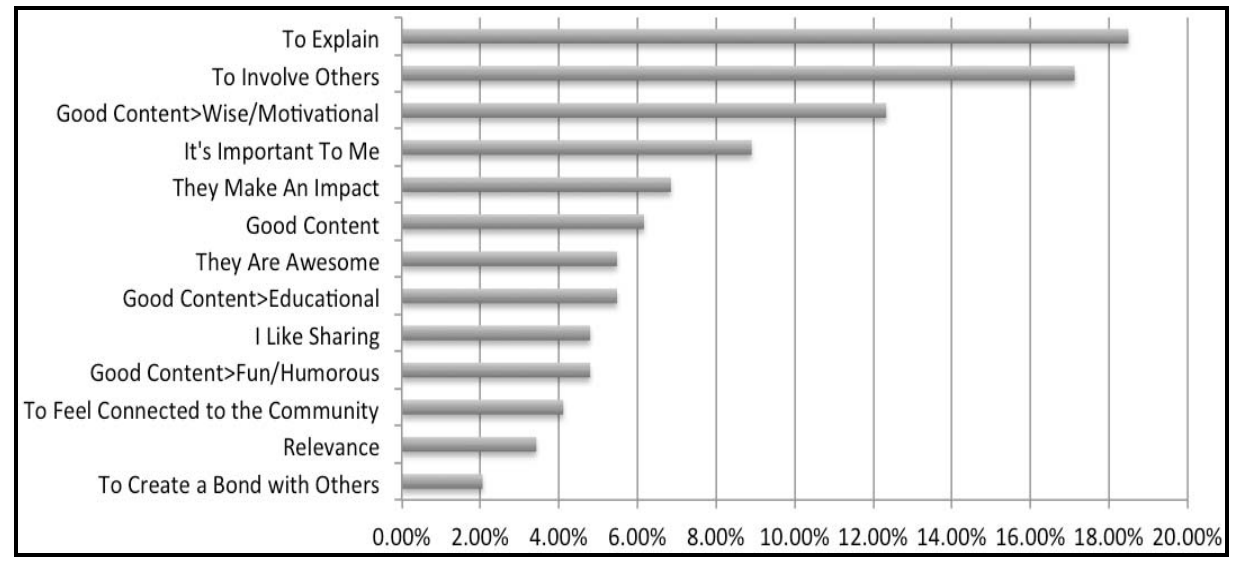

The different motivations for sharing were coded into ten different reasons. The most recurrent one was 'to explain', a code used every time a participant reported that he or she had shared a story whenever somebody (Nerdfighter or not) had specifically asked him or her to explain what a particular activity or artefact meant. For example, a respondent explained:

“To help clear things up, sometimes it doesn’t make sense why Hank or John might be doing something; someone in the comments will ask a question. Occasionally I answer it.”

The next most frequent reason for sharing stories was coded as 'to involve others', which was a code used when a participant explained that his or her aim was to invite more people to join the community. The following response illustrates this idea:

"I tutored a girl three years younger then me at my old school. She was being bullied badly, and felt left out. Her other peers weren't interested in being 'smart' and cared more about being popular. She felt a lot like an outcast, like she just didn't belong. I’ve felt that way before and I know how terrible it feels. I thought introducing her to Nerdfighteria would introduce her to a community where she could be herself and feel like she belonged, and was important."

The third most frequent reason for sharing stories was because they were motivational or inspirational, a reason that was sub-coded under 'good content'. This code was used when respondents reported they shared the Vlogbrothers videos with others because they were good content that could be 'educational', 'fun/humorous', or 'wise/motivational'. As this reason for sharing stories refers more specifically to Vlogbrothers videos, and not so much to the community's culture, this category of reasons is not analysed here.

The fourth most frequent reason for sharing was coded as 'it's important to me', and it reflected the sentiment that one shares the community's stories because they are personally significant to him or her, or because they feel proud to be a part of the community. For example, a respondent stated:

“I think there's something pretty special about being part of this community. Being able to call myself a Nerdfighter, even to someone who doesn't really understand what that means, makes me feel like I'm part of something important. A community like this helps change the world, I think, even in some ways, by not ever forgetting to be awesome!” 
Another popular reason for sharing stories was because 'they make an impact', a code used whenever participants shared stories because they were about making some kind of impact in the world, which makes them worth telling. This code is similar to that of 'they are awesome', which also refers to the fact that these stories should be shared. They express the sentiment that these stories are worth sharing because of how influential they are. For example, a respondent explained:

"I've told my parents and even others at my work about the way the community comes together to help others, usually to demonstrate how online and fandom communities come together for the greater good.”

The code 'I like sharing' was used whenever a participant reported that they shared the various stories because that is part of their personalities, so their motivation was not specifically founded in the community.

\section{Discussions and implications}

\subsection{Major discussion points}

The top five stories described as being more important to understand the community's culture were those about the origin of the community, followed by inside jokes and shared values, stories about Esther Earl, and stories about fundraising projects. Many respondents also reported that they thought there were no specific essential stories in this community's culture: that either any story would be good enough to understand the culture, or that the culture could not be fully understood through stories. This specific reason was used whenever respondents interpreted the question to mean what newcomers would need to know to be part of the community, so their reaction is actually a reflection of wanting to remain inclusive and welcoming to newcomers. Nevertheless, the top five stories reflect the main features of narratives that let them be used as tools for culture formation. Mainly, these stories reflect marker events, breach of canonicity, intentional state entailment, particularities, and referentiality.

In terms of collective narrative accrual, participants reported that they do in fact share stories with others, and they explained that their five top reasons for doing so are to explain them to others, to involve others in the community, to share wise/motivational content, because they find them personally important, or because they are stories about making an impact in the world. This idea follows Bruner's (1991) proposal about narratives actually accruing through people sharing them to make up a culture. Moreover, the two most frequent reasons for having shared stories with other community members were to explain and to involve others in the community. This idea lines up with the concept of sense of community, which is partly composed by the feeling of being influential in other members of a community (McMillan and George, 1986). A sense of community has been found to have statistically significant effects on the likelihood of people participating in narrative accrual for culture formation in this OC (Leyton Escobar, 2013). More specifically, it was found that the higher the sense of community, the higher the likelihood a member would actually share narratives with other members or decide to join the community based on his or her knowledge of such narratives. The fact that the reasons for sharing narratives line up with this concept provides more evidence for that effect. 


\subsection{Practical implications}

These findings are useful to understand the role narratives play in culture formation and in participation in OCs, as well as the importance of culture and values in these communities. When Faraj et al. (2011) discussed the need to research narratives, they wondered if narratives in OCs needed to have an agency to be effective or if they just needed to be stories of times past. But as it was found in this research, the stories that are more relevant to a community are not ones with an agency, but those about the community itself, about members of the community doing something significant, and about the community achieving goals together.

In the case of the Nerdfighter community, the narratives that were labelled more 'essential' for the culture were: those about the origins of the community, which included inside jokes that emerged throughout its history; those about members doing significant things (e.g., the Green brothers creating the Vlogbrothers channel, Esther Earl making the best of her situation to spread a message of love); and those about the community coming together for great causes (e.g., stories about fundraising projects, including the Kiva Lending Team and the Project for Awesome).

Moreover, this research also shows that narratives do accrue to form a culture in OCs, and that community members do take an active part in sharing and accruing narratives. Participants reported sharing narratives in order to make them clear for others, to involve others in the community, or to share wise/motivational content. They also reported sharing narratives because they felt they were personally important to them, and that they were worth sharing because they were about people making an impact in the world.

Considering the types of essential narratives explained here, as well as the reasons for sharing them, can be useful when trying to steer a process of culture formation in OCs. The significant features of narratives found in this research can serve as a selection filter to pick which narratives are more influential in different communities. It should also be noted that spreading these type of narratives in OCs might be key not only for channelling participation, but also for creating more cohesive communities. These are key implications that can be useful for community managers in charge of online outreach for both private companies and non-profit organisations. If community members are more likely to be involved in an OC when sharing the type of narratives discussed here, community managers can obtain better results from their outreach strategies by utilising these narratives, when they exist, or by creating activities that generate them (e.g., activities that promote members coming together for specific causes, or ones that promote individual stories that are relevant to the culture while being extraordinary or inspirational).

\subsection{Limitations and future research}

There are two main limitations in this study First, the self-selection process of the participants. Although the online survey was posted in four different platforms to reach a broader scope of community members, it is likely that only those most invested in the community actually took the time to fill it out, which may have caused a bias in the results.

The other limitation is that this case study is focused on only one community, so the results may not be entirely generalisable. However, future research might focus on whether or not other OC members can collectively identify narratives relevant to their 
communities, and to what type of narratives turn out to be more important for culture formation. In the case that the same types of narratives are singled out, it would also be worth it to see if such narratives have an effect on the participatory behaviour of the community.

\section{References}

Boyd, D. (2011) 'Social network sites as networked publics: affordances, dynamics, and implications', in Papacharissi, Z. (Ed.): A Networked Self Identity, Community, and Culture on Social Network Sites, pp.39-58, Routledge, Taylor and Francis Group, New York.

Brown, A.D. (2006) 'A narrative approach to collective identities', Journal of Management Studies, Vol. 43, No. 4, pp.731-753.

Bruner, J. (1991) The Narrative Construction of Reality, Vol. 18, No. 1, pp.1-21, The University of Chicago Press.

Burgess, J.E. and Green, J. (2008) 'Agency and controversy in the YouTube', Community paper presented at the Proceedings IR 9.0: Rethinking Communities, Rethinking Place - Association of Internet Researchers (AoIR) Conference, IT University of Copenhagen, Denmark.

Faraj, S., Jarvenpaa, S.L. and Majchrzak, A. (2011) 'Knowledge collaboration in online communities’, Organization Science, Vol. 22, No. 5, pp.1224-1239, doi: 10.1287/orsc.1100.0614.

Leyton Escobar, M. (2013) The Key is not to Forget to be Awesome: An Analysis of the Use of Narratives as Tools for Channeling Participation in Online Communities, Master thesis, University of Twente Repository Home, Publication Number 64036 [online] http://essay. utwente.nl/64036/.

Maloney-Krichmar, D. and Preece, J.D. (2002) 'The meaning of an online health community in the lives of its members - roles, relationships and group dynamics', Paper presented at the International Symposium on Technology and Society, ISTAS '02.

McMillan, D.W. and George, D.M.C. (1986) 'Sense of community: a definition and theory', Journal of Community Psychology, Vol. 14, pp.6-23.

Paolillo, J.C. (2008) 'Structure and network in the YouTube core', Paper presented at the 41st Hawaii International Conference on System Sciences.

Preece, J.D. (2001) 'Sociability and usability in online communities: determining and measuring success', Behaviour \& Information Technology, Vol. 20, No. 5, pp.347-356, doi: 10.1080/01449290110084683.

Preece, J.D., Maloney-Krichmar, D. and Abras, C. (2003) 'History of emergence of online communities', in Wellman, B. (Ed.): Encyclopedia of Community, Bershire Publishing Group, Sage.

Schein, E.H. (2004) Organizational Culture and Leadership, 3rd ed., Jossey-Bass Inc., San Francisco.

Xiao, L. (2006) 'Culture in virtual communities', in Dasgupta, S. (Ed.): Encyclopedia of Virtual Communities and Technologies, pp.102-104, Information Science Reference, Hershey, PA.

Yates, D., Wagner, C. and Majchrzak, A. (2009) 'Factors affecting shapers of organizational wikis', Journal of the American Society for Information Science and Technology, doi: 10.1002/asi.21266. 